\title{
El agonismo del poder en la concepción foucaulteana del gobierno
}

\author{
Marilina Del Valle \\ UNNE-CONICET \\ marilinadv@hotmail.com
}

Recibido 03/07/2017

Aprobado 31/07/2017

\section{Resumen}

El presente trabajo se propone una aproximación a la noción foucaulteana de "gobierno" en la que se haga hincapié en su dimensión agonística. Nuestro objetivo es, en principio, resaltar la distancia que separa el concepto de sujeción que envuelve tal noción, por una parte, de la idea de un poder constituido sobre la base del consenso y la legitimidad, y, por otra, de la idea de una dominación homogénea e ineluctable. Para ello, se plantea que, a partir de una serie de reflexiones de Foucault en torno de la noción de gobierno, es posible trazar una naturaleza constitutivamente frágil en los estados de sujeción, en virtud de la cual es posible trazar un intenso dinamismo en sus procesos de constitución y, concomitantemente, una profunda heterogeneidad en su configuración.

\section{Palabras clave \\ Agonismo - gobierno - contraconducta - sujeto - libertad}

\section{Abstract}

The present paper proposes an approach to the Foucauldian notion of government emphasizing its agonistic dimension. Our aim is, in the first place, to stress the gap between the concept of subjection involved in such notion and two elements: on the one hand, the idea of a power constituted on the basis of consensus and legitimacy, and, on the other hand, the idea of an homogeneous and almighty domination. To that purpose, the paper states that, in Foucault's works regarding the notion of "government", it is the constitutively tragic nature of states of subjection 
(restored and deepened by the author in this new conceptualization of power) what allows to understand the heterogeneity of states of government. That is, the convergence, in government strategies, of an inclination to a subtle and undirect induction, and the persistence of repression and coercion.

\section{Keywords}

Agonism - government - counter-conduct - subject - freedom

\section{Introducción}

El objetivo del presente trabajo es realizar una aproximación a la noción foucaulteana de "gobierno" haciendo hincapié en su dimensión agonística. Nuestro objetivo es, en principio, poner de relieve la distancia que separa el concepto de sujeción que envuelve tal noción, por una parte, de la idea de un poder constituido sobre la base del consenso y la legitimidad, y, por otra, de la figura de una dominación homogénea e ineluctable.

Para ello, se rastrea la presencia de dicha dimensión agonística en una serie de textos del autor francés que, no obstante su carácter exploratorio y puntual, ofrecen definiciones de la noción de gobierno en el sentido antes señalado, en virtud de las cuales es posible delinear una grilla de análisis que luego puede verse plasmada en las investigaciones de tal autor. Nos proponemos trazar, entonces, un recorrido por el problema de las relaciones entre conductas y contraconductas, la definición del gobierno en virtud de las relaciones inestables entre sujeciones y subjetivaciones, y aquella que lo entiende como una correlación agónica con las libertades.

De acuerdo con esto, nuestra hipótesis es que, a través de tales textos, es posible avanzar en la reconstrucción de la naturaleza constitutivamente frágil y en permanente tensión de las estrategias de gobierno, naturaleza que conferiría un intenso dinamismo a sus procesos de constitución y revestiría de una profunda heterogeneidad a su configuración. 


\section{Las tensiones entre conductas y contraconductas}

Si bien el análisis de las contraconductas que Michel Foucault lleva a cabo en el marco de su seminario de 1978, Seguridad, territorio, población, puede ser visto como un primer signo del desplazamiento que Foucault realiza en la década del 80 hacia los problemas de la libertad, la ética y subjetividad ${ }^{1}$, también puede ser leído como una clave de lectura de la exploración que tal autor realiza en torno de la historia de la gubernamentaldiad. Dentro de dicho marco, la noción de contraconducta permite poner de manifiesto el carácter ni bélico ni finalista, sino agonístico, de la dinámica del gobierno. Esto es, el singular modo de confrontación que pone de manifiesto dicha dinámica, y esto aun cuando las relaciones de poder sean concebidas por Foucault, bajo la grilla del gobierno y la conducción de conductas, procurando conferir algún espacio al problema de las relaciones de interacción desplegadas entre individuos o grupos, o entre "gobernantes y gobernados" 2 .

En la clase del primero de marzo de $1978^{3}$, Foucault introduce el neologismo "contraconducta" para referir a las múltiples formas de disidencia religiosa engendradas en las fronteras del cristianismo desde el momento mismo en que emergía tal configuración de poder ${ }^{4}$. Para abordar este análisis el primer movimiento que realiza el autor francés es desmarcarlo de lo que entiende como un estudio de los "topes externos" ${ }^{5}$ del poder pastoral. A partir de su renuncia al análisis de “...resistencias activas... con las cuales el pastorado chocó de frente", el autor francés decide hacer un recorte en la grilla de análisis de las resistencias y atender a las “...las

\footnotetext{
${ }^{1}$ Ver. Borg, Kurt. "Conducting critique: reconsidering Foucault's engagement with the subject". En: Symposia Melitensia, volumen 11, 2015 y Castro-Gómez, Santiago. Historia de la gubernamentalidad. Razón de estado, liberalismo y neoliberalismo en Michel Foucault. Bogotá, Siglo del Hombre Editores, 2010, pp. 103-111.

${ }^{2}$ Ver. Foucault, Michel. Nacimiento de la biopolítica. Trad. Horacio Pons. Bs. As., Fondo de Cultura Económica, 2008, p. 254.

${ }^{3}$ Ver. Foucault, Michel. Seguridad, Territorio, Población. Trad. Horacio Pons. Bs. As., Fondo de Cultura Económica, 2006, pp. 221-261.

${ }^{4}$ En las clases precedentes a su análisis de las contraconductas, Foucault ensaya una investigación en torno a la figura del poder pastoral y el modo de racionalidad que encierra desde los primeros siglos del cristianismo. Sería posible entender que, en aquellas clases, tal poder era presentado como el principal precedente y como una importante condición del movimiento en virtud del cual, a partir de la modernidad, la vida de los individuos y de las poblaciones recae bajo el radio de problematización de los gobiernos. En su análisis del poder pastoral el autor francés describe con minucia el conjunto entremezclado de principios y procedimientos en virtud de los cuales se pone en circulación una forma de conducción cotidiana tendiente a envolver a los individuos en una red de dependencias permanente y exhaustiva. Dentro de esta configuración, el principio de obediencia resulta tan capital como la apelación a la voluntad de los individuos a partir de la singular relación que mantienen con la verdad verdad que debe ser descubierta en el interior del individuo, declarada, progresivamente enseñada. Ver. Ibíd., pp. 146-219.

${ }^{5}$ Ibíd., p. 225.
} 
formas de ataque y contraataque que se dieron en el campo mismo del pastorado" ${ }^{6}$. A partir del énfasis en estos topes internos que constituirían las resistencias al pastorado concebidas bajo la forma de contraconductas, el autor francés -emplazado en la problemática de las relaciones entre gobernantes y gobernados o la conducción de conductas- busca inclinar su estudio hacia aquellos elementos que trazaron, junto a aquel poder, una dinámica consistente en un incesante juego de tensiones, apropiaciones mutuas, efectos inesperados, incesantes recuperaciones y reasimilaciones efectuadas con mayor o menor éxito, que introduce un nivel de correspondencia y permeabilidad entre conductas y contraconductas. "La lucha...", sostiene Foucault con respecto a este punto, se desenvuelve a partir de "...la utilización permanente de elementos tácticos que son pertinentes en el combate antipastoral, toda vez que forman parte, de una manera incluso marginal, del horizonte general del cristianismo"7.

En tal sentido, para el autor francés, la partición entre conductas y contraconductas parece referir a instancias con respecto a las cuales no resulta posible establecer una cabal distinción de naturaleza, y, por ende, cuyo modo de relacionamiento no admite ser pensado a partir de una lógica de oposiciones. Tanto las conductas como las contraconductas remiten a maneras singulares de conducción. Esto lleva a un punto en el que el autor francés, en nuestra consideración, busca hacer hincapié: el hecho de que las contraconductas no refieran a movimientos que se levanten contra el poder pastoral desde el exterior no conduce a conferirles un carácter exactamente reformista, ni tampoco reactivo. Cuando el análisis se recorta en el nivel de las contraconductas, se remite a acciones que no se acaban en la desobediencia y despliegan una dimensión afirmativa y que revisten por contrapartida, una racionalidad propia. Con respecto a este punto, Foucault señala “...los movimientos que trato de indicar tienen a buen seguro una productividad, formas de existencia, de organización, una consistencia y una solidez que la palabra puramente negativa de desobediencia no puede abarcar" ${ }^{8}$. En un mismo movimiento, las contraconductas se configuran bajo la forma de grietas en el poder pastoral e

\footnotetext{
${ }^{6}$ Ibídem.

${ }^{7}$ Ibíd., p. 260.

${ }^{8}$ Ibíd., p. 236.
} 
intensifican algunos de sus puntos marginales abriendo la posibilidad de otras formas de conducta.

Entre las prácticas adversas al pastorado que vendrían a constituirse, de acuerdo con el autor francés, bajo la forma de contraconductas, se encuentra una práctica tradicionalmente asociada a la religión cristiana como el ascetismo. En este sentido, Foucault refiere al "ascetismo indefinido" ${ }^{9}$ desarrollado por algunos movimientos gnósticos, cuya extrema condenación de la existencia material, cuando no conducía al suicido se hacía extensiva hacia todo tipo de autoridad y normatividad establecida por instancias terrenales. La difusión, dentro de estos grupos, de la idea de que es necesario “...destruir la materia por el agotamiento del mal que reside en ella"10, traducía el camino hacia la salvación en una práctica de "transgresión sistematizada"11. El autor francés señala, asimismo, que, por tres razones, en el marco de la vida monacal constituía una verdadera preocupación el control de los excesos ascéticos de los anacoretas. En principio, porque envolvía a quien lo practicaba en una relación con su propio sufrimiento en la que el papel del director se desplazaba hacia un segundo plano. En segundo lugar, porque si bien las prácticas ascéticas de los anacoretas revestían un carácter procesual en escala de dificultad creciente semejante a aquél que encerraba la relación del pastor y su dirigido en la dirección de conciencia, desde el momento en que el criterio la dificultad se trasladaba hacia la tolerancia hacia el sufrimiento del propio asceta, no podía ser sino sólo éste último quien dirigiera, conociera y midiera su propio proceso. Finalmente, porque el ascetismo del anacoreta instalaba al sujeto en una "justa" permanente con respecto a sí mismo y los otros que rivalizaba con el pastorado cristiano, en la medida en que en este último tal relación se trazaba a partir de los principios de obediencia y humildad ${ }^{12}$.

\footnotetext{
${ }^{9}$ Ibíd., p. 226.

${ }^{10}$ Ibídem.

${ }^{11}$ Ver ibíd., pp. 226 y 227.

${ }^{12}$ Ver Ibíd., pp. 244-247. En su descripción de los otros casos de contraconductas que se enfrentaron al pastorado, Foucault menciona el trazado de formas de vida comunitaria bajo relaciones jerárquicas diferentes de la red de sumisiones instaurada por el poder pastoral, en las que se podía constatar la institucionalización de esquemas de inversiones sistemáticas de las jerarquías, el establecimiento de relaciones de obediencia recíproca, o bien la creación de la figura de los "elegidos" que no necesitan de la mediación del pastor para salvarse. De un modo análogo, tanto la mística -por envolver al sujeto en una experiencia de carácter extático e incomunicable irreductible a la "dirección de conciencia" y claramente incompatible con el carácter progresivo de la enseñanza de la verdad en la relación pastoral- la exaltación de la escritura -por suprimir la mediación del pastor en la enseñanza- como las creencias escatológicas -por postular la inminencia de la llegada de Dios invalidando así todo tipo de conducción terrenal- son presentadas por Foucault bajo la forma de movimientos de resistencia erigidos, en mayor o menor medida, en tensión con el proceso de conformación del poder pastoral. Ver ibíd., pp. 249-259.
} 
En virtud del análisis de tales prácticas ascéticas y de la relación de tensión que mantenían con el pastorado, Foucault singulariza, correlativamente, la ascética pastoral, afirmando que constituye un llamado a "...una renuncia permanente, una renuncia a la voluntad y sólo a la voluntad, y un despliegue de la conducta del individuo en el mundo"13. Esto es, en virtud de la relación entre conductas y contraconductas se establece una precisión en la lectura que asocia el ascetismo cristiano a una práctica ético-política focalizada en la cabal degradación del cuerpo.

La concepción de las relaciones de poder a partir de las tensiones entre conductas y contraconductas, así concebida, mantiene un lazo directo con otra de las propuestas analíticas sugeridas por el autor francés en el marco de su seminario de 1979: una "lógica de la estrategia" ${ }^{14}$ bajo cuya lente sea posible percibir la heterogeneidad en tensión. En el manuscrito redactado para la clase del 10 de enero de 1979, en referencia a los cruces acontecidos, en el marco de la emergencia de la gubernamentalidad liberal, entre la limitación extrínseca del principio del mayor gobierno asumida por el campo jurídico y la limitación “interna” a la práctica gubernamental exigida a partir del desarrollo del saber económico y su problematización de la población, tal autor sugiere:

“...no son dos sistemas que se suceden, y ni siquiera que van a entrar en un conflicto insalvable. Heterogeneidad no quiere decir contradicción sino tensiones, fricciones, incompatibilidades mutuas, ajustes exitosos o malogrados, mezclas inestables, etc. También quiere decir tarea retomada sin cesar, porque nunca se acaba, para establecer ya sea una coincidencia, ya sea, al menos, un régimen común" ${ }^{15}$.

En la siguiente clase, el autor francés propone, en el contexto de la mencionada problemática e interpelando nuevamente a la noción de heterogeneidad ${ }^{16}$, sustituir,

\footnotetext{
${ }^{13}$ Ibíd., p. 248.

${ }^{14}$ Ver. Foucault, Michel. Nacimiento de la biopolítica., op. cit., p. 62. Asimismo, en la conferencia "¿Qué es la crítica?", pronunciada en el año 1978, poco tiempo después de la citada clase del primero de Marzo sobre las contraconductas, Foucault ya hablaba de una "lógica de las interacciones" en términos muy similares. Ver. Foucault, Michel. Qué es la crítica?. En: Daimon: Revista Internacional de Filosofía, $\mathrm{n}^{\circ} 11,1995$. En: http://revistas.um.es/daimon/article/view/7261, p. 16.

${ }^{15}$ Ibídem.

16 “...lo que es preciso recordar es que la heterogeneidad nunca es un principio de exclusión o, si lo prefieren, la heterogeneidad jamás impide la coexistencia, ni la unión, ni la conexión. Digamos que es justamente ahí y en ese
} 
para el análisis de las configuraciones históricas, la tendencia hacia la armonización de los opuestos por una "lógica de la estratégica". En este sentido, afirma que: "La función de esa lógica de la estrategia es establecer las conexiones posibles entre términos dispares y que siguen dispares. La lógica de la estrategia es la lógica de la conexión de lo heterogéneo y no la lógica de la homogeneización de lo contradictorio" ${ }^{17}$.

\section{La concepción del gobierno como "equilibrio inestable" entre sujeciones y}

\section{subjetivaciones}

En una conferencia del año $1980^{18}$ titulada "El origen de la hermenéutica de sí", ya emplazado en la problemática ética, el autor francés invoca la noción de gobierno como grilla de análisis en virtud de la cual sea posible percibir el proceso en virtud del cual el pastorado cristiano tendió a transformar las prácticas de examen de conciencia paganas frente a la búsqueda de asimilarlas. En ese contexto, Foucault definió al gobierno en términos que presentan todavía alguna familiaridad con su previa alusión al ejercicio del poder pastoral y a la gubernamentaldiad como "conducción de conductas":

“Gobernar a la gente, en el sentido lato de la palabra, no es una manera de forzarla a hacer lo que quiere quien gobierna; siempre hay un equilibrio inestable, con complementariedad y conflictos, entre las técnicas que se ocupan de la coerción y los procesos mediante los cuales el sí mismo se construye o se modifica por obra propia"19

En el momento de la formulación de este nuevo concepto de gobierno, el autor francés empezaba a dar forma a la tercera pieza de su recorrido teórico, que vendría a

tipo de análisis donde se hace valer, donde es menester hacer valer, bajo la pena de caer en el simplismo, una lógica que no sea dialéctica". Ibíd., p. 62.

${ }^{17}$ Ibídem.

${ }^{18}$ Foucault, Michel. El origen de la hermenéutica de sí. Trad. Horacio Pons, Bs. As., Siglo XXI., 2016.

${ }^{19}$ Ibíd., p. 45. En El uso de los placeres, sin invocar la categoría del gobierno pero en términos similares, Foucault alude a una articulación conflictiva entre diferentes dimensiones de la moral: "Estas morales "orientadas hacia la ética" (y que no coinciden forzosamente con las morales de lo que se ha dado en llamar "renuncia ascética) han sido muy importantes en el cristianismo al lado de las morales "orientadas hacia el código": entre ellas a veces hubo yuxtaposiciones, a veces rivalidades y conflictos, a veces acuerdo". 
articularse a las anteriores y que ya se anticipaba en el análisis de las contraconductas: el análisis del campo de las relaciones consigo mismo y las prácticas de $\mathrm{si}^{20}$, las formas a través de las cuales los sujetos se constituyen a sí mismos y a su propia verdad en la búsqueda de alguna de alcanzar un estado de felicidad o de salvación. Sería posible entender que, para tal autor, en las indagaciones que lleva a cabo a principios de los años 80 , el agonismo todavía constituye un rasgo indispensable a la hora de definir al poder. A partir de ahora, las relaciones de poder van a ser concebidas en virtud de un delicado equilibrio, antes que con los sujetos, con los procesos a través de los cuales los sujetos se conocen y 'se gobiernan' a sí mismos.

A pesar de su carácter esquemático, pueden extraerse algunas implicancias interesantes de la antes citada alusión al "gobierno". La misma provee una concepción singular del "equilibrio" constitutivo de los puntos de gobernabilidad, en la cual se articulan dos niveles por lo común contrapuestos: el de las complementariedades y el de los conflictos entre el poder y la voluntad de los sujetos. A partir de la fórmula que afirma que el gobierno debe ser visto como articulación agónica e inestable entre sujeción y subjetivación, el concepto el poder no necesariamente pierde su carácter eminentemente confrontativo por desplegar -incluso efectivamente- una relación más 'benévola' con la voluntad del sujeto.

Huelga decir que la "complementariedad" entre las técnicas de poder y los procesos de subjetivación de ninguna manera remiten a la instancia de un "contrato". En la medida en que el gobierno no acontece y se desenvuelve en el nivel de los agentes racionales, los 'puntos de gobierno', en lo fundamental, nunca encuentran su punto de apoyo en decisiones originadas en una voluntad consciente, tomadas por sujetos de derecho universales y preexistentes al momento de instauración de una sociedad política. Lo interesante sería entonces señalar, antes bien la relación de desplazamientos que se producen entre una y otra forma de concebir la correspondencia entre los procedimientos de poder y los sujetos. El autor francés afirma que la complementariedad del gobierno remite a un equilibrio constitutivamente inestable. Este equilibrio es pensado como el efecto actual del entrelazamiento estratégico de múltiples y móviles puntos de 'transacción', esto es, el

\footnotetext{
${ }^{20}$ Ver. Foucault, Michel. Foucault, Michel. Historia de la sexualidad 2. El uso de los placeres. Trad. Soler Martí. Bs. As., Siglo XXI, 2010.
} 
efecto de un conjunto de cálculos estratégicos en el devenir de las relaciones entre, por una parte, los poderes sujetos a una modificación constante de su propia práctica, $y$, por otra, los modos de existencia virtuales para sujetos posibles constituidos siempre en entramados de gobierno. Entrelazamiento con respecto al cual el autor francés no va a dejar de insistir en el carácter problemático y accidentado de su marcha (como así tampoco va a dejar de atribuir a dicho rasgo el principio de su vitalidad y mutabilidad permanente).

Pero, a partir de la citada definición, tampoco habría que pensar que la sujeción a través de la complementariedad con la voluntad suponga una suerte de dominación homogénea que en virtud de su carácter sutil, huidizo o intangible devenga aún más profunda e irreversible, porque de esta manera no podría entenderse cabalmente la inestabilidad de los entramados de gobierno y se estaría asimilando el nivel del gobierno al de la ideología. Si bien es posible pensar a los estados de gobierno desplegando una mayor sutilidad e incluso eficacia, este atributo no excluye el agonismo que envuelven. El gobierno se presenta, entonces, bajo la forma de un accidentado despliegue que abarca, articula y pone en juego un amplio y heterogéneo rango de procedimientos, que van desde el extremo de la represión hasta el de la construcción de espacios abiertos para el despliegue libre de las acciones e interacciones entre los sujetos. Como contrapartida, la dimensión de la subjetividad, que viene a concebirse, en sí misma, emplazada dentro del campo móvil de un "gobierno" en el cual se distinguen tanto zonas negativas como afirmativas, barre con la imagen esencialista de un sujeto opuesto externamente al poder.

\section{El agonismo entre el poder y la libertad}

En su texto "El sujeto y el poder" del año 1983, abocado a esbozar una conceptualización del poder afín al estado actual de sus investigaciones sobre el sujeto, Foucault pone aún mayor énfasis en el carácter agónico de las relaciones de gobierno $^{21}$. El desafío de tal autor en dicho texto, es realizar una indagación del origen

\footnotetext{
${ }^{21}$ Foucault, Michel. "The subject and power". En: Foucault, Michel. "The subject and power". En: H. Dreyfus y P. Rabinow. Michel Foucault beyond structuralism and hermeneutics. Chicago, The University of Chicago Press, 1983, pp. 208-226.
} 
y la naturaleza de un poder cuya única forma de realidad es su puesta en ejercicio. Esto es, plantear la pregunta acerca de si es posible "...imaginar un poder que unifique en él, un qué, un porqué y un cómo"22.

En el marco de tal búsqueda Foucault define al "gobierno" como un conjunto de acciones sobre acciones originado en el proceso de puja con las libertades. Para tal autor, considerar el poder desde el punto de vista de su puesta en ejercicio, $y$, por consiguiente, sin partir del supuesto de su relación de exterioridad con la libertad, implica no confundirlo con las estructuras fijas en las que ulteriormente se integra ${ }^{23}$. También desarticula dos de las más difundidas concepciones del mismo: las que afirman que se origina en el consentimiento y aquellas que lo asimilan al ejercicio desnudo de la violencia. El poder, afirma, no puede ser identificado con la soberanía entregada a algunos a través de un contrato, porque este acto supone la sustracción por medios legítimos de las libertades de acción, estas últimas, componentes determinantes para el ejercicio del poder. Con respecto a la violencia, ésta traduce aquella mecánica de sustracción a términos ilegítimos (al ejercerse por medio de la fuerza sobre los cuerpos "cierra todas las posibilidades de acción" y no puede dar lugar a las resistencias.

Cuando el poder es definido como un conjunto de acciones ordenado a actuar sobre las acciones posibles y sobre las "posibles invenciones que pueden abrirse" ${ }^{24}$, se presupone necesariamente su origen en la dinámica de reciprocidad agónica que, en su despliegue, las estrategias de poder mantienen con las libertades codificadas, en este contexto, bajo la forma de resistencias. La naturaleza constitutivamente agónica del poder considerado de esta forma, se debe a que el poder nunca puede alcanzar un punto de saturación porque su operatividad misma tiene como punto de partida a las libertades. Esta situación, para el autor francés, no hace otra cosa que empujar incesantemente a las estrategias de poder hacia sus propios términos:

“Toda intensificación, toda extensión de las relaciones de poder para hacer que el insubordinado se someta puede sólo resultar en los límites del poder. Este último llega a su término final, tanto en el tipo de acción que reduce al otro a

\footnotetext{
${ }^{22}$ Ibíd., p. 217.

${ }^{23}$ Ibíd., pp. 219-222.

${ }^{24}$ Ibíd., p. 220.
} 
la impotencia total (en cuyo caso la victoria sobre el adversario reemplaza al ejercicio del poder) como en la confrontación con aquellos a quienes gobierna y su transformación en adversarios" 25 .

Tanto la dominación como la guerra constituyen, para Foucault, los límites del poder. Las relaciones de poder corren el riesgo, de un momento a otro, o bien de paralizarse al convertirse en dominaciones unívocas, o bien de abandonar el agonismo y la posibilidad de “...manipular e inducir acciones de forma calculada..." ${ }^{26}$ para desencadenar la "lucha a muerte" "27, el antagonismo de la confrontación entre adversarios. Es por eso que las estrategias de gobierno van a encontrarse 'enfrentadas', principalmente, a un horizonte de posibilidades más o menos abierto para los individuos y los grupos. En estas condiciones, el "por qué" se unifica al "qué" y al "cómo" del poder, en la medida en que en tal concepción el movimiento de interjuego entre las sujeciones y las subjetivaciones concibe a la tensión entre las mismas como un principio que determina y modifica perpetuamente la actualidad de las estrategias de poder, sus tácticas y sus procedimientos.

A partir de este tipo de conceptualización del poder, puede entenderse que, paralelamente a la misma, Foucault sugiera atender al valor metodológico de las resistencias y señale que deberían ser tomadas como un principio que conduzca a hacer inteligibles las relaciones de poder $^{28}$. De esta manera, es posible pensar que las resistencias, específicamente tal como se desplegaron en el momento de gestación de las relaciones de poder, por el hecho mismo de la afectividad que condensan y por el agonismo -y concomitante permeabilidad- que las relaciones de poder envuelven, se convierten, al mismo tiempo en la medida por excelencia de estas últimas.

\section{Conclusiones}

El presente trabajo buscó esbozar una indagación en torno del carácter agónico del poder cuando este es concebido bajo la rúbrica del gobierno en una serie de investigaciones de Michel Foucault posteriores a 1978, postulando que la problemática

\footnotetext{
${ }^{25}$ Ibíd., p. 225.

${ }^{26}$ Ibídem.

${ }^{27}$ Ibídem.

${ }^{28}$ Ibíd., pp. 210 y 211.
} 
del enfrentamiento resulta insoslayable para comprender la dinámica del poder en los textos estudiados.

A tales efectos, hemos buscado exponer dicha perspectiva como la presentación de un nuevo modo posible de concebir el enfrentamiento, en virtud del agonismo entre instancias con respecto a las cuales no resulta posible establecer una cabal distinción de naturaleza, y que suponen, todas ellas, contrapuntos emplazados en los márgenes del poder: las contra-conductas, los procesos de subjetivación y las libertades. No obstante, si bien un punto recurrente en todas estas figuras es que son definidas por la fragilidad que instalan en las relaciones de poder, cada una de ellas introduce diferentes matices que permiten aproximarse a la singular naturaleza de la confrontación que encierra la noción de gobierno.

Se procuró mostrar que esta nueva aproximación a la cuestión del enfrentamiento ya podía avizorarse, en la concepción del poder formulada por Foucault en el citado curso de 1978, en el elemento particular de las contra-conductas. Allí, la concepción del poder bajo la forma de una correlación agónica entre las conductas y las contra-conductas ${ }^{29}$, puede señalarse como el elemento clave, el impulso sólo a partir del cual las configuraciones de gobierno se vuelven permeables e incorporan elementos heterogéneos. La textura del poder reviste, desde este punto de vista, constitutivas fisuras. En el estudio foucaulteano de las contra-conductas, tales formas de existencia "difusas y moderadas" que producen sin embargo efectos sobre el poder pastoral o sobre el gobierno de los Estados, se emplazan en un nivel ético, el cual deviene en sí mismo político en el particular contexto de una configuración pastoral de poder que atraviesa los modos de existencia, las actitudes o el temple moral de los individuos. Sin embargo, a la luz de la perspectiva de la correlatividad fundadora de conductas y contra-conductas, el nivel ético o reflexivo del poder pastoral podría leerse antes que como un grado de mayor elaboración o evolución del proceso de sujeción -por colonizar la interioridad del sujeto- como un resultado de la mencionada correlación ${ }^{30}$.

\footnotetext{
${ }^{29}$ Foucault, Michel. Seguridad, territorio, población, op. cit., pp.225-227.

${ }^{30}$ En indagaciones llevadas a cabo años posteriores, Foucault procura poner de manifiesto dicha condición al resaltar el carácter adverso que las prácticas de sí paganas (tales como el examen de conciencia) supusieron para una configuración pastoral de poder desde su punto de emergencia, carácter adverso cuyo resultado puede encontrarse en el intento de formulación de una espiritualidad cristiana. Ver. Foucault, Michel. Foucault, Michel. La hermenéutica del sujeto. Trad. Horacio Pons. Bs. As., Fondo de Cultura Económica, 2008, pp. 241-153.
} 
Intentó mostrarse también que el componente agónico del gobierno es sugerido por el autor francés en la citada conferencia de 1980, en referencia a las relaciones entre las tecnologías de dominación y aquellas en virtud de las cuales los sujetos se conocen y transforman a sí mismos. Esto es, se mostró que el gobierno es presentado bajo la forma de una transacción permanente y accidentada entre estas dos dimensiones. En tal sentido, dicha noción permite pensar un tipo singular de relación de poder en virtud de la cual la contraposición categórica habitualmente trazada entre la coerción y la voluntad individual aparece de otro modo. Esta contraposición se complejiza a partir de la concepción del gobierno como una zona, amplia y diversificada, en la que se emplazan y superponen las sujeciones y las subjetivaciones bajo una dinámica de tensión. En este sentido, la reconceptualización del poder desde la óptica del gobierno y la relación agónica entre sujeción y subjetivación buscaría, no tanto hacer hincapié en la necesidad de repensar la naturaleza del poder ni la del sujeto, tomados como elementos aislados entre sí (tampoco se reduciría al análisis de las formas como el poder asimila los procesos de subjetivación, o, a la inversa, cómo los subjetivaciones vienen a configurar entramados de poder legítimos). Antes bien, la perspectiva del gobierno haría énfasis en la necesidad de atender a la correlatividad y los permanentes y constitutivos reenvíos entre las dinámicas del poder y las de los sujetos, al tiempo que pondría de manifiesto la permeabilidad y fragilidad inherente a ambas instancias, señalando que no pueden ser tomadas por elementos exteriores entre sí. Esto en la medida en que tanto el poder como los sujetos presuponen y se constituyen bajo los efectos de entramados de gobierno.

Con referencia, finalmente, al análisis foucaulteano de las relaciones entre el poder y la libertad en "El sujeto y el poder", se intentó señalar que el gobierno supone la existencia de un campo de posibilidades más o menos abierto dentro del cual los sujetos son constituidos bajo la forma misma de la posibilidad, una posibilidad que conlleva asimismo la posibilidad de las invenciones. En dicho análisis pudo verse que, notablemente, la definición formulada del poder bajo la forma de un conjunto articulado de acciones ordenado a constituir campos de posibilidades, no sólo no excluye la posibilidad de una consideración agónica de las relaciones de poder, sino que abre un mayor espacio a la misma. Esto en la medida en que dicha concepción 
desprende la idea del poder como estructuración de libertades del propio agonismo de aquél. Así, paradójicamente, el mismo factor que permite entender la inclinación de las estrategias de poder por la inducción sutil e indirecta sobre la represión o la coerción, da lugar a concebir a ese mismo poder como una configuración en perpetuo riesgo. Podría entenderse, entonces, que la aproximación al concepto de poder en "El sujeto y el poder" otorga una clave de lectura para entender la "delicadeza" atribuida al poder en la definición provista por la citada conferencia de 1980, esto es, permite leerla designando un modo de relación cuya sutileza descansa en su inherente fragilidad.

En consecuencia, puede afirmarse que los textos analizados en el presente trabajo ponen de relieve la configuración inherentemente agónica del enfoque gobierno.

\section{Bibliografía}

- Borg, Kurt. "Conducting critique: reconsidering Foucault's engagement with the subject". En: Symposia Melitensia, volumen 11, 2015

- Castro-Gómez, Santiago. Historia de la gubernamentalidad. Razón de estado, liberalismo y neoliberalismo en Michel Foucault. Bogotá, Siglo del Hombre Editores, 2010,

- Foucault, Michel. Seguridad, Territorio, Población. Trad. Horacio Pons. Bs. As., Fondo de Cultura Económica, 2006

- ------- Qué es la crítica?. En: Daimon: Revista Internacional de Filosofía, n 11, 1995. En: http://revistas.um.es/daimon/article/view/7261

- ------.-- El origen de la hermenéutica de sí. Trad. Horacio Pons, Bs. As., Siglo XXI.,

placeres. Trad. Soler Martí. Bs. As., Siglo XXI, 2010.

- - --- "The subject and power". En: Foucault, Michel. "The subject and power". En: H. Dreyfus y P. Rabinow. Michel Foucault beyond structuralism and hermeneutics. Chicago, The University of Chicago Press, 1983

Pons. Bs. As., Fondo de Cultura Económica, 2008 